\title{
Autonomous Learning Mode based on a Four-Element Teaching Design for Visual Communication Course
}

\author{
https://doi.org/10.3991/ijet.v15i19.17399 \\ Yan Zhao ${ }^{(\bowtie)}$, Yuemeng Luo \\ University of Science and Technology Liaoning, Liaoning, China \\ plapla1001esina.com
}

\begin{abstract}
With the development and improvement of information transfer efficiency in this era, visual communication has people's life and communication. However, the thinking in the traditional visual communication course is fixed, and students' learning enthusiasm is weak. Hence, this study proposes an autonomous learning mode by using a four-element teaching design. First, we propose relevant knowledge and ability, learning task, supporting program, and special practice as four elements related to education program. Second, we integrate them into the autonomous learning model to help students achieve learning transfer. Third, we use the new K-means algorithm to collect students' autonomous learning behavior data in the online course of visual communication and divide the data into three levels (high, medium, and low levels) for analysis. Finally, we design autonomous learning teaching cases for visual communication by using the proposed four-element teaching design and analyze the teaching effect. Our results show that the proposed learning mode enables a long learning video watching time for students, which in turn produces a high percentage of completed tasks. This result verifies that the application of the autonomous learning mode based on four-element teaching design can improve students' autonomous learning ability. Therefore, this mode is worth promoting.
\end{abstract}

Keywords-Four-element teaching; autonomous learning; new K-means algorithm; visual communication.

\section{$1 \quad$ Introduction}

The 21st century is an era of rapid development of knowledge. With the development of Internet and modern communications technology, information transfer between people has become increasingly convenient and efficient. As a special form of art, visual communication starts to be gradually accepted [1]. Visual communication regards "human" as the subject and focuses on human subjective feelings and psychological presentation to meet human spiritual needs, thereby further conveying and delivering messages [2]. However, the specialty of college visual communication has numerous problems, such as fixed and rigid classroom teaching mode, too many class hours for theoretical part, and lack of effective interaction step. All these problems lead to students' low learning enthusiasm. Moreover, teaching equipment is outdated. 
Consequently, students' experience is poor when applying software for relevant design. The gap between teaching cases and market demand changes is large, and the rapid pace of era development and change is difficult to pursue [3]. A four-element teaching design mode is an example of transformation of contemporary teaching design theory, which receives an increasing attention. It has a wide application prospect in various educational fields, such as vocational and online education. However, the visual communication course has still no corresponding teaching reform report.

In this study, we choose visual communication as the main content of teaching practice to investigate the feasibility of an autonomous learning model based on a four-element teaching design. First, we develop a new four-element teaching design that conforms to the teaching content of visual communication. Second, for students with low learning initiative, we integrate an autonomous learning model. Finally, we adopt a new K-means algorithm to collect, sort, and analyze the learning data of online course by using the above integrated mode. We propose an online course teaching mode with autonomous learning function. The proposed method can effectively improve learning effect for design major students and cultivate considerable design personnel conforming to the demands of the new media era.

\section{State of the Art}

Under the background of the new media era, visual communication design course faces an unprecedented challenge of development transformation. The traditional teaching model cannot meet social demands for talents and students' desire for improving the level of expertise. Compared with traditional design category, art design under the background of the new media era drives the development of visual communication design because of its advantages, such as virtual reality, integration, and diversification. Developed countries have started early in exploring visual communication design. For instance, "Visual communication design" has become popular at the World Design Conference in Tokyo, Japan. The content of visual communication design includes the design of newspapers, periodicals, posters, and other printed publicity materials and communications media, such as films, television programs, and electronic advertising boards. Expressive design conveying relevant contents to the eyes is generally called visual communication design [4]. With the rapid development of social network and multimedia technologies, people may transfer information through all kinds of methods and symbols. This situation imposes unprecedented opportunity and challenge for students majoring in visual communication design. In the current college education, diversified multimedia teaching methods are needed for visual communication design to help students apply various technical means and improve their design abilities. Rourke et al. [5] developed an assessment method for advanced art and design specialty, proposed the connection between course design and learning dilemma and autonomous learning task, and applied blog log case teaching method. They found that these methods contributed to the cultivation of students' learning ability. Rintoul et al. conducted a teaching experiment for the practice course of art design major. Using a mixed method, they focused on CS in the BTEC Extend- 
ed Diploma in Art and Design. They found that a seemingly progressive flight from a discrete CS to a designed integration form may bring unintended negative outcomes. In view of their study, we recommended some ways for course teams to think over their practices. Kim et al. [7] applied the studio teaching method in the design major and adopted a design studio project. They organized students from the Republic of Korea and Malaysia to design economically affordable housing for one semester and found that the creation of design studio could stimulate students' innovative thinking and arouse their learning motivation to continue pursuing their major.

In China, the major of visual communication design has been developed late. With the continuous development of economy and the society, the demand for visual communication design talents is increasing, and the requirements are also improving. Educators in the visual course point out a series of problems, such as the backwardness of teaching ideas and lack of practice in class. They perceive that traditional design idea and thinking should be changed first, and students' practice in class should be enhanced to alter traditional teaching [8]. With the continuous development of information technology, increasing number of scholars start to realize that educational reform is urgent. Zhang [9] applied experiential teaching method in college visual communication teaching and found that this method could improve teaching effect and promote students' understanding of specialized course knowledge and practical operation ability. Li [10] integrated modern apprenticeship teaching method in visual communication teaching and added hand-painting art elements according to the features of visual communication major in vocational education while considering the training objectives of vocational colleges. The results showed that the new teaching method was more beneficial to the improvement of students' vocational ability. According to the above research results, an increasing number of new methods and thoughts have been applied in visual communication teaching. Qiu et al. [11] applied task, problem, and project-driven method in visual communication teaching and showed that it played an important role for visual communication teaching development and talent training. Zhang [12] introduced a five-star teaching mode for practice and application to motivate students' creativity and laid a foundation for cultivating high-quality applied talents. However, these teaching methods focus on the change of teachers' classroom teaching method and lack of training of students' autonomous learning ability. At present, visual communication major is faced with a new situation of social development. Traditional education and teaching mode cannot give play to ideal value, and relevant teaching contents cannot be used to cultivate students' vocational skills effectively. Hence, reform and innovation research on the teaching mode of visual communication is needed.

This study proposes an autonomous learning mode in accordance with a fourelement teaching design and applies it during visual communication. This study offers some innovations. First, we apply a four-element teaching design in the practice course of visual communication and design four teaching modules considering the course content of visual communication. These teaching modules include relevant knowledge and ability, learning task, supporting program, and special practice. Second, we design this teaching method to focus on the development of students' autonomous learning ability and learning, which is different from traditional teacher- 
centered method. Third, we use the new K-means algorithm for the first time to collect, classify, and analyze the data about students' autonomous learning in the online course of visual communication to provide objective data for evaluating whether this teaching method could improve students' autonomous learning ability. We hope that the new teaching method could provide new reference and enlightenment for design major teaching and learning.

\section{Autonomous Learning Mode Based on Four-Element Teaching Design in Visual Communication Teaching}

\subsection{Integration of four-element teaching design in visual communication teaching}

A four-element teaching design can develop professional and comprehensive abilities and promote knowledge transfer. It describes four elements related to the teaching program (relevant knowledge and ability, learning task, supporting program, and special practice), as shown in Fig. 1.

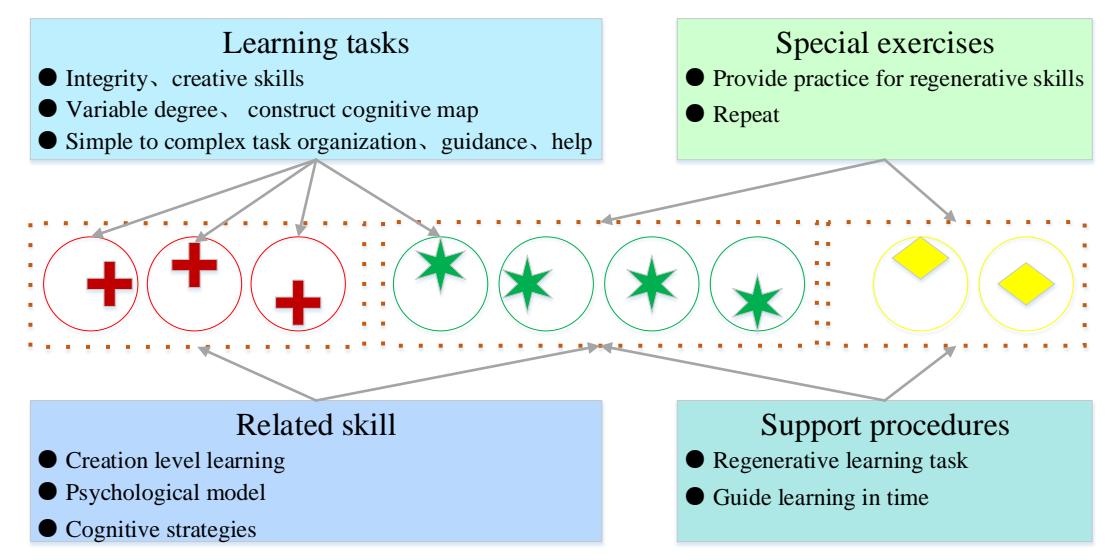

Fig. 1. Four elements of four-element teaching design

As shown in Fig. 1, learning task is the fundamental element. The assignment, project, and problem may be learning tasks. Students need to complete learning tasks under real or virtual environment. Learning tasks should cover technical knowledge used to complete the tasks. Students should not just have creative skills to solve and think over problems but also own regenerative skills. Learning tasks are used as the "drivers" of inductive learning. When the degree of variation exists in learning tasks, inductive learning is effective and students can learn, generalize, and construct cognitive schema from experience. In the process of completing tasks, students generally complete the simple tasks first before proceeding to the difficult ones. In the tasks with high complexity, teachers provide much guidance and help at first and then reduce guidance and help gradually. Finally, students complete their tasks without 
teacher's guidance or help and then enter the next learning task with higher complexity than the previous one.

According to Fig. 1, relevant knowledge and ability help students to complete creative tasks by providing original and required knowledge for learners. Relevant knowledge and ability help learners construct the cognitive schema that explains how to organize (mental models) in a field and how to solve problems (cognitive strategy). Relevant knowledge and ability are related to complexity of learning tasks. With the same complexity of learning tasks, relevant knowledge and ability of tasks are also the same. Relevant knowledge and ability required by the learning task of the next level of complexity extends relevant knowledge and ability at the last level of complexity.

The above relevant knowledge and ability can assist students in completing the tasks at the creation level, whereas the supporting program can help them complete the tasks at the regeneration level. When students use the supporting program for the first time, this program is also a part of the learning task. After students have master relevant knowledge in the later period, their demand for the supporting program become lesser than before until it is revoked in the end.

Through continuous practice in the learning process, students can perform routine operation proficiently in the end. When the quantity of practice involved in the learning task is insufficient, additional special practice is required. Teachers not just implement the supporting program in the learning task scene at the regeneration level but also in the special practice sometimes.

\subsection{Online visual communication course teaching based on students' autonomous learning ability}

Autonomous learning is a process in which individuals and their environment and behaviors interact with one another. Students need self-regulation in the whole learning process. Psychological development of self-learning mainly includes the planning, control, and self-reflection stages.

In the planning stage, students should conduct goal setting first. Then, they should select suitable autonomous learning strategies. Self-motivated belief is the internal impetus of autonomous learning and an important part of self-learning. In the control stage, students need to concentrate through self-control and find learning deficiency and deviation through self-observation. In the self-reflection stage, students should know their learning situation and the reasons for learning deviation through selfevaluation, reason analysis, and summary. 


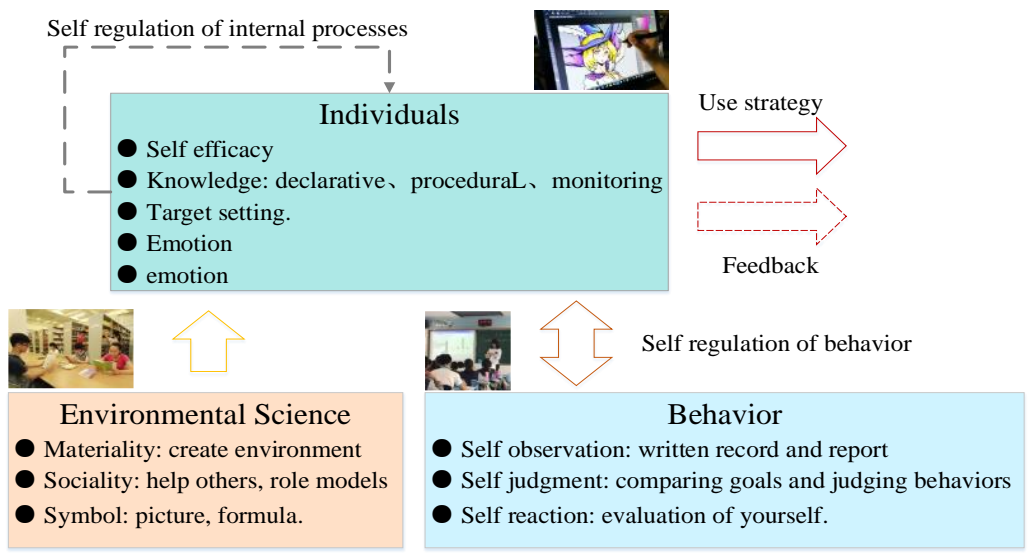

Fig. 2. Autonomous learning model

\subsection{Implementation program of autonomous learning mode based on four- element teaching design in visual communication course}

On the basis of a four-element teaching design and autonomous learning model, we develop a frame diagram of a learning mode that conforms to visual communication design and teaching content, as shown in Fig. 3. In this figure, logo design is an activity that requires the use of simple Photoshop graphic design software. The teacher uses a multimedia tool to guide the students in learning and understanding logo design and makes them master basic logo design through certain practice.

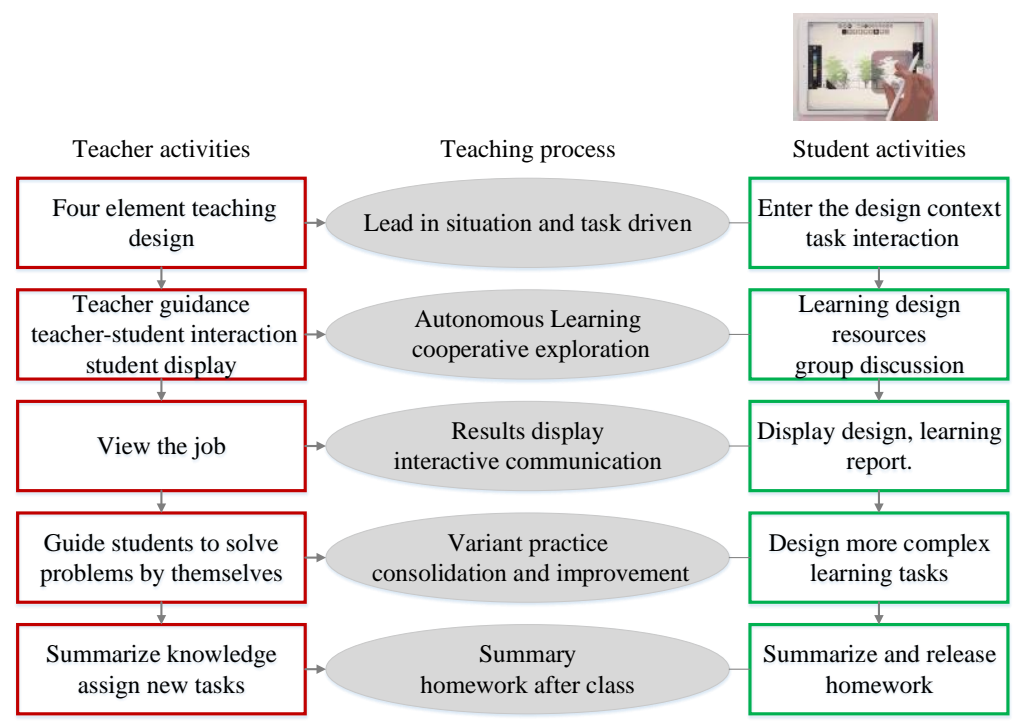

Fig. 3. Frame diagram of autonomous learning mode based on four-element teaching design 
First, the teacher should conduct a four-element teaching design and design learning tasks, relevant knowledge and skills, supporting program, and special practice. In this teaching mode, procreate drawing software is used as the design software. Learning task setting starts from a PowerPoint presentation of popular business logos, such as Nike, Qianye Glasses, and McDonald's. The teacher should let the students know learning tasks, upload the videos, and test the teaching materials related to the learning task to the network platform. The teacher can know students' learning situations and progress any time. The students can view learning resources uploaded for selflearning through the network platform and discuss online with their team members. The teacher can check students' learning progress and answer their questions. The students can independently design simple logos through autonomous learning and then exhibit the logos and expound design ideas. Then, the teacher can provide comments on the students' works. According to the logos designed by the students, the teacher pushes advertising leaflet design and other variant exercises. Subsequently, the students finish the exercises as required. The teacher explains the students' works. Figs. 4 and 5 show the students' work design. In the end, the teacher organizes the class to provide summary and conclusion. The students may raise their knowledge and doubts in the discussion area. Finally, the teacher assigns homework according to the students' learning situations.

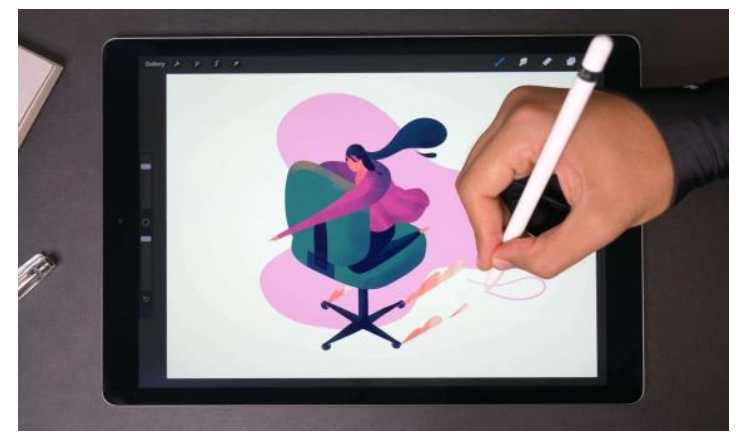

Fig. 4. Students' independent design screenshot I in autonomous learning model

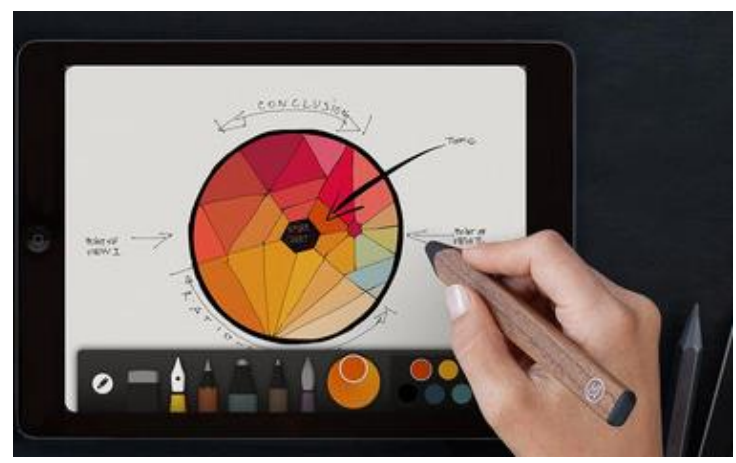

Fig. 5. Students' independent design screenshot II in autonomous learning model 


\subsection{Analysis of students' autonomic learning behavior in online course of visual communication based on new $K$-means algorithm}

K-means algorithm refers to K-mean clustering analysis algorithm. The steps of this algorithm are as follows:

1) Divide the data to be analyzed into $K$ groups

2) Randomly select $K$ objects as the initial center of clustering

3) Calculate the distance between every object with teach sub-center of clustering

4) Assign each object to the nearest center of clustering

The center of clustering and the object assigned represent a cluster. Whenever an object is assigned, the center of clustering should be calculated again. This process is repeated until the termination condition is met.

We use the new K-means algorithm to improve the original algorithm. Then, we use the three-layer Bayesian probability model called latent dirichlet allocation (LDA) to model and extract themes in this study. Fig. 6 shows the LDA-based clustering model.

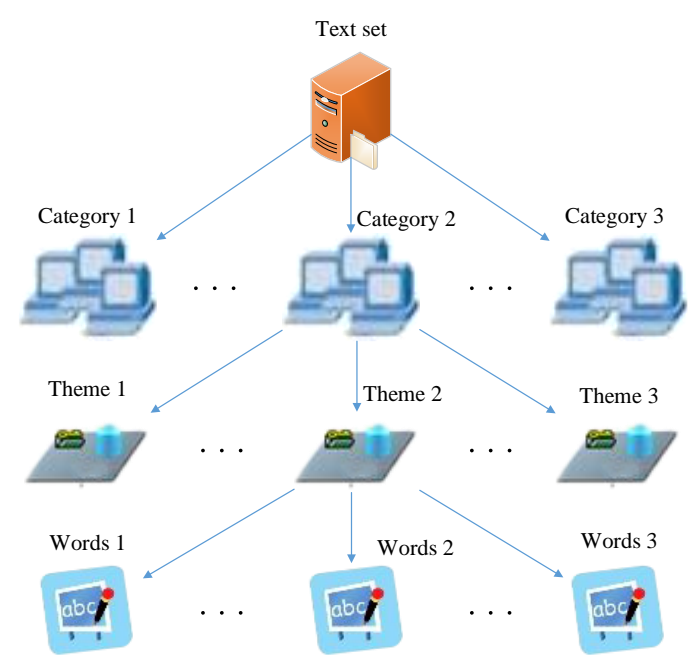

Fig. 6. Clustering model based on new K-means algorithm

We assume that the text set has $\mathrm{N}$ themes, $\mathrm{J}$ texts, and $\mathrm{V}$ different words. The definitions of variables and steps involved in generating the ith text $d_{i}$ by using LDA are as follows: $\left({ }^{d}\right.$ represents the ith text, ${ }^{Z_{k}}$ refers to the theme; ${ }^{w_{i}}$ is a word; $\theta$ represents polynomial distribution of themes; and $\varphi$ means polynomial distribution of words). 
From the text $d_{i}$ (with ${ }^{N_{i}}$ words), (1) extract a $Z_{k}$ from $\theta$ (including $\mathrm{N}$ themes); (2) randomly draw a word ${ }^{w_{i}}$ from $\varphi_{\text {corresponding to }} Z_{k}$; and (3) repeat steps (1) and (2) for $N_{i}$ times. The above process results in the following distribution formula:

$$
p\left(w_{i}, z_{i}, \theta, \varphi \mid \alpha, \beta\right)=\prod_{n=1}^{N_{i}} p\left(w_{i, n} \mid \varphi_{z_{i, n}}\right) p\left(z_{i, n} \mid \theta_{i}\right) p\left(\theta_{i} \mid \alpha\right) p(\varphi \mid \beta)
$$

The probability of initializing the word $\mathrm{t}$ by ${ }^{w_{i, n}}$ is:

$$
p\left(w_{i, n}=t \mid \theta_{i}, \varphi\right)=\sum_{k=1}^{N} p\left(w_{i, n}=t \mid \varphi_{k}\right) p\left(z_{i, n}=k \mid \theta_{i}\right)
$$

The likelihood function expression of text set is:

$$
p(W \mid \theta, \varphi)=\prod_{i=1}^{I} p\left(w_{i} \mid \theta_{i}, \varphi\right)=\prod_{i=1}^{I} \prod_{n=1}^{N_{i}} p\left(w_{i, n} \mid \theta_{i}, \varphi\right)
$$

In this study, we use the distance function Jensen-Shann (JS function) for the definition and $D_{i s}(p, q)$ to express the distance between theme probability distribution vectors $\mathrm{p}$ and $\mathrm{q}$.

$$
D_{i s}(p, q)=\frac{1}{2}\left(\sum_{i=1}^{k} p_{i} \ln \frac{p_{i}}{q_{i}}+\sum_{i=1}^{k} q_{i} \ln \frac{q_{i}}{p_{i}}\right)
$$

The main steps of the algorithm are as follows: (1) determine the number of themes; (2) select the optimal theme; and (3) gain the initial center of clustering. We also determine the number of themes: $\left({ }^{d i}\right.$ represents the similarity between theme $z_{j}$ and theme $z_{i}$.

$$
d_{j i}=\sum D_{i s}\left(z_{j}, z_{i}\right)
$$

Subsequently, we take the mean value:

$$
\bar{d}=\frac{2 \sum_{j=1}^{n-1} \sum_{i=j+1}^{n} d_{j i}}{n \cdot(n-1)}
$$

When $\bar{d}$ is minimum, $\mathrm{n}$ is the optimal number of themes. We use LAD to model for the text set and solve the matrix for the modeled text vector to obtain $n$ themes. 
Then, we select $\mathrm{m}$ typical themes from $\mathrm{n}$ themes. The degree of importance $T l_{i}\left(t_{j}\right)$ represents the important degree of theme ${ }^{t_{j}}$ in text $d_{i}=\left(t_{1}, t_{2}, t_{3}, \cdots, t_{n}\right)$; when $T l_{i}\left(t_{j}\right)$ is larger, the theme ${ }^{t_{j}}$ is more important. If $T_{i}\left(t_{j}\right)$ represents conditional probability of ${ }^{t}{ }_{j}$ for text $d_{i}=\left(t_{1}, t_{2}, t_{3}, \cdots, t_{n}\right)$, then

$$
\begin{gathered}
T l_{i}\left(t_{j}\right)=T_{i}\left(t_{j}\right) \cdot I_{i}\left(t_{j}\right) \\
T_{i}\left(t_{j}\right)=P\left(t_{j} \mid d_{i}\right)=\frac{D T(i, j)}{\sum_{k=1}^{n} D T(i, k)} \\
I_{i}\left(t_{j}\right)=\ln \frac{1}{p\left(d_{i} \mid t_{j}\right)}=\ln \frac{\sum_{k=1}^{I} D T(k, j)}{D T(i, j)}
\end{gathered}
$$

where DT is a "text-theme" vector, and I is the overall number of texts to be clustered. According to the above three formulas, the expression of $T l_{i}\left(t_{j}\right)$ is

$$
T l_{i}\left(t_{j}\right)=\frac{D T(i, j)}{\sum_{k=1}^{n} D T(i, k)} \cdot \ln \frac{\sum_{k=1}^{I} D T(k, j)}{D T(i, j)}
$$

where $T l\left(t_{j}\right)$ represents the importance degree of theme $t_{j}$ in the text set.

$$
T l\left(t_{j}\right)=\sum_{i=1}^{J} T l_{i}\left(t_{j}\right)
$$

where $\mathrm{J}$ refers to the total number of texts.

Error $\delta$ of importance degree represents the error between the sum of importance degree of the optimal $\mathrm{m}$ themes and the sum of importance degree of all $\mathrm{n}$ themes.

$$
\delta=1-\frac{\sum_{j=1}^{m} T l\left(t_{j}\right)}{\sum_{j=1}^{n} T l\left(t_{j}\right)}=\frac{\sum_{j=m+1}^{n} T l\left(t_{j}\right)}{\sum_{j=1}^{n} T l\left(t_{j}\right)}
$$

We sort all themes in descending order according to the value of $T l\left(t_{j}\right)$ and obtain the distribution diagram of importance degree. The first $\mathrm{m}$ themes are optimal. The value of $\mathrm{m}$ can be determined through $\delta$. We use Formula (13) to solve the sum 
of distance between every sample ${ }^{d_{i}^{j}}$ and barycenter ${ }^{k_{j}}$. Finally, we obtain k initial centers of clustering for K-means clustering.

$$
H=\sum D_{j s}\left(k_{j}, d_{i}^{j}\right)
$$

We apply the new K-means algorithm in this study for clustering analysis of the data in the process of students' autonomous learning, as shown in Fig. 7.

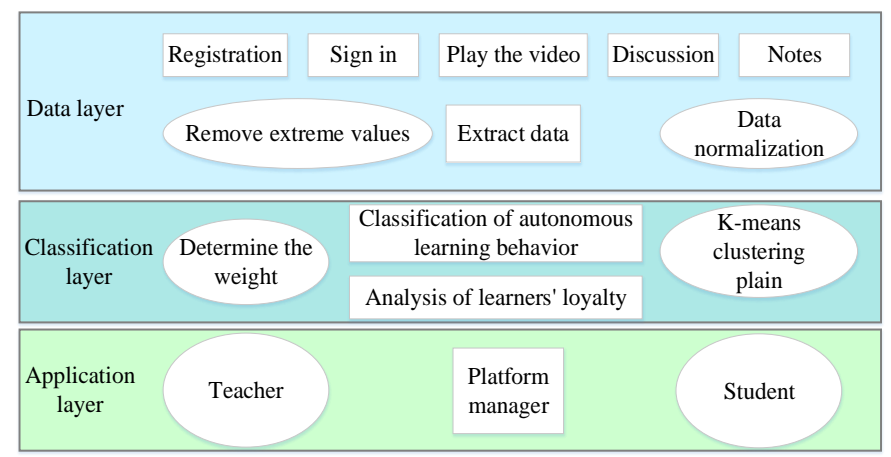

Fig. 7. K-means-based learning behavior classification

First, we employ RFL to extract the data of number of registrations, login, video playing, discussion, and records, and then we establish a data classification index system. Second, we use the K-means clustering analysis algorithm for the clustering analysis of data. By analyzing the students' loyalty index, we can classify their autonomous learning into the following categories: continuous learning, discontinuous learning, active learning, wait-and-see learning, and independent learning. The teacher can understand the students' autonomous learning situation and learning progress in time through the platform and improve the teaching strategy.

Fig. 8 shows the general framework diagram of behavior analysis in the autonomous learning process and classifies the students' autonomous learning behaviors into high, medium, and low levels. Consequently, we can analyze well the category and data definition in the learning process. 


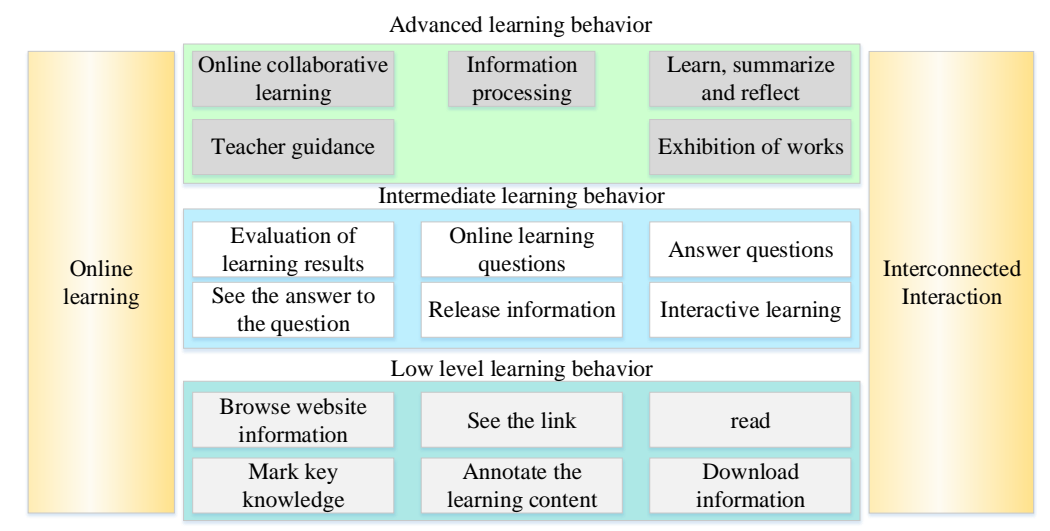

Fig. 8. General framework diagram of autonomous learning behavior analysis

The students' behaviors in an autonomous online learning are complex, and online platform log record can record well related data. The server collects time and behavior data by recording the students vide watching duration and login IP address and identifies information and notes, cleans, filters, and recombines the data in the backend program of the system. Finally, the processed data are saved to the backend database. The teacher and the students can check behavior reanalysis data at the client server through corresponding modules.

We conduct the K-means clustering analysis for 3569 learning behavior path data. We use the path step as the variable, and 0 means students do not use learning behavior (give up after learning behavior in the first step). The maximum value of iterations is 11 , and the number of clustering is 3 . Table 1 shows the initial center of clustering based on the new k-means analysis. Table 2 shows historical records of the 11 iterations.

Table 1. Initial center of clustering

\begin{tabular}{|l|c|c|c|}
\hline \multirow{2}{*}{ Number of iterations } & \multicolumn{3}{|c|}{ Clustering } \\
\cline { 2 - 4 } & 1 & 2 & 3 \\
\hline Variable 1 & 2 & 3 & 7 \\
\hline Variable 2 & 3 & 7 & 0 \\
\hline Variable 3 & 7 & 1 & 0 \\
\hline Variable 4 & 7 & 6 & 0 \\
\hline Variable 5 & 7 & 1 & 0 \\
\hline Variable 6 & 0 & 6 & 0 \\
\hline Variable 7 & 0 & 7 & 0 \\
\hline
\end{tabular}


Table 2. Historical records of iterations

\begin{tabular}{|l|c|c|c|}
\hline \multirow{2}{*}{ Number of iterations } & \multicolumn{3}{|c|}{ Change of center of clustering } \\
\cline { 2 - 4 } & $\mathbf{1}$ & $\mathbf{2}$ & $\mathbf{3}$ \\
\hline Variable 1 & 5.544 & 5.612 & 5.134 \\
\hline Variable 2 & 5.278 & 5.322 & 5.342 \\
\hline Variable 3 & 5.123 & 5.109 & 5.211 \\
\hline Variable 4 & 5.111 & 5.043 & 5.112 \\
\hline Variable 5 & 5.142 & 5.034 & 5.098 \\
\hline Variable 6 & 5.125 & 5.206 & 5.093 \\
\hline Variable 7 & 5.101 & 5.176 & 5.043 \\
\hline Variable 8 & 5.103 & 5.012 & 5.065 \\
\hline Variable 9 & 5.096 & 5.129 & 5.032 \\
\hline Variable 10 & 5.102 & 5.092 & 5.076 \\
\hline Variable 11 & 5.084 & 5.054 & 5.031 \\
\hline
\end{tabular}

Table 3 shows the final center of clustering after 11 iterations. Table 4 shows the final number of clustering cases after 11 iterations.

Table 3. Final center of clustering

\begin{tabular}{|l|c|c|c|}
\hline \multirow{2}{*}{ Number of iterations } & \multicolumn{3}{c|}{ Change of center of clustering } \\
\cline { 2 - 4 } & $\mathbf{1}$ & $\mathbf{2}$ & $\mathbf{3}$ \\
\hline Variable 1 & 3 & 3 & 2 \\
\hline Variable 2 & 3 & 3 & 3 \\
\hline Variable 3 & 4 & 4 & 2 \\
\hline Variable 4 & 5 & 4 & 2 \\
\hline Variable 5 & 1 & 4 & 2 \\
\hline Variable 6 & 4 & 2 & 2 \\
\hline Variable 7 & 2 & 6 & 2 \\
\hline
\end{tabular}

Table 4. Number of clustering cases

\begin{tabular}{|l|c|c|c|c|}
\hline \multicolumn{3}{|c|}{ Clustering } & Effective & Absent \\
\hline 1 & 2 & 3 & 3569 & 0 \\
\hline 1330 & 1447 & 792 & & 0 \\
\hline
\end{tabular}

\section{$4 \quad$ Teaching Example and Effect}

\subsection{Teaching example}

We design an autonomous learning mode of visual communication in accordance with a four-element teaching design in this study, as shown in Table 5. This method includes the teaching analysis, teaching design, and teaching development stages. In the teaching analysis stage, we analyze the students' learning situation, psychological status, and autonomous learning ability to understand the design-related knowledge learned by the students and their proficiency degree for a design software (such as Photoshop). Then, we investigate the learned knowledge and skills. This investigation 
is useful for new knowledge to be learned because it identifies the key and difficult points of knowledge to be learned and the time required. In the design stage, we design the learning objective, learning time, learning order, learning description, and learning achievement assessment. We also develop the data and activity types of online autonomous learning, prepare the draft, and perform a trial teaching. Finally, we adjust and develop the final online autonomous learning materials and practical activities on the basis of the situation of trial teaching.

Table 5. Implementation of autonomous learning mode based on four-element teaching design

\begin{tabular}{|c|c|c|c|}
\hline Stage & Analysis & Design & Development \\
\hline \multirow{6}{*}{$\begin{array}{l}\text { Key } \\
\text { points }\end{array}$} & $\begin{array}{l}\text { 1. Understand students' learning } \\
\text { situation, psychologic status, } \\
\text { demand and autonomous learning } \\
\text { ability, etc.; }\end{array}$ & $\begin{array}{l}\text { 1. Transform learning objec- } \\
\text { tives into the performance } \\
\text { objective; }\end{array}$ & $\begin{array}{l}\text { 1. Determine online auton- } \\
\text { omous learning materials } \\
\text { and practice types }\end{array}$ \\
\hline & $\begin{array}{l}\text { 2. Define cognitive skills, emotion- } \\
\text { al skills and psychological skills } \\
\text { required in teaching as well as } \\
\text { learning tasks and learning objec- } \\
\text { tives; }\end{array}$ & $\begin{array}{l}\text { 2. Determine importance of } \\
\text { knowledge points in each unit } \\
\text { of teaching content and the } \\
\text { time needed; }\end{array}$ & $\begin{array}{l}\text { 2. Prepare online autono- } \\
\text { mous learning materials and } \\
\text { drafts of practical activities }\end{array}$ \\
\hline & $\begin{array}{l}\text { 3. Understand what skills the } \\
\text { learner has learned and what design } \\
\text { software the learner has mastered, } \\
\text { and learn about their degree of } \\
\text { proficiency in software use; }\end{array}$ & $\begin{array}{l}\text { 3. Properly adjust learning } \\
\text { order and time according to } \\
\text { the specific autonomous } \\
\text { learning objective and com- } \\
\text { plexity of knowledge points; }\end{array}$ & $\begin{array}{l}\text { 3. Provide learners with } \\
\text { online autonomous learning } \\
\text { materials and activities for } \\
\text { trial teaching }\end{array}$ \\
\hline & $\begin{array}{l}\text { 4. Analyze complexity and im- } \\
\text { portance of each knowledge unit as } \\
\text { well as the time needed for learn- } \\
\text { ing. }\end{array}$ & $\begin{array}{l}\text { 4. Consolidate unit-based } \\
\text { teaching and determine main } \\
\text { goals of each unit; }\end{array}$ & $\begin{array}{l}\text { 4. Adjust and make online } \\
\text { autonomous learning mate- } \\
\text { rials and practical activities } \\
\text { according to trial teaching }\end{array}$ \\
\hline & & $\begin{array}{l}\text { 5. Explain contents of each } \\
\text { class hour and skills to be } \\
\text { mastered in detail; }\end{array}$ & $\begin{array}{l}\text { 5. Develop training contents } \\
\text { for teachers, etc. }\end{array}$ \\
\hline & & $\begin{array}{l}\text { 6. Design the method and } \\
\text { requirements for online } \\
\text { evaluation of autonomous } \\
\text { learning results. }\end{array}$ & \\
\hline
\end{tabular}

\subsection{Teaching effect}

We adopt a visual communication design course that covers 56 learning tasks, which are divided into three types: document, video, and online testing. We assign the students under the program a total of 45 video tasks, 1 document task, and 10 testing tasks. We take the freshmen in Class 1 and Class 2 in the school of computing as the experimental subjects. Class 1 has 55 students, and Class 2 has 52 students. We use the new mode for Class 1 and the traditional mode for Class 2. We set the duration of learning for one semester. We analyze and record the students vide watching duration by using the statistical function of online learning platform. Table 6 shows the results. The maximum duration and average duration of Class 1 are longer than those of Class 2 , indicating that the new mode is more beneficial to the improvement of students' autonomous learning ability than the traditional one. Table 6 displays the completion 
of 56 tasks. The proportion task completion in Class 1 is as high as $100 \%$, which is higher than that of Class 2. The average completion proportion of Class 1 is also higher than that of Class 2. This result verifies again that the students develop stronger autonomous learning ability and participate in learning more actively in the new mode than in the traditional one.

Table 6. Video viewing time and Completion of task points

\begin{tabular}{|l|c|c|}
\hline & Class 1 & Class 2 \\
\hline Maximum viewing time (minutes) & 800.2 & 724.9 \\
\hline Average viewing time (minutes) & 436.8 & 302.3 \\
\hline Fastest progress & $100 \%$ & $97.10 \%$ \\
\hline Average progress & $87.60 \%$ & $75.30 \%$ \\
\hline
\end{tabular}

The traditional teaching mode cannot fully arouse students' learning interest because they cannot reach the expected learning effect. In the proposed learning mode, we import design cases on the market through the task design link and transfer the classroom teaching to real practical work scene. This process contributes to the improvement of students' learning enthusiasm. We ask the items of tasks by imitating customer's design demand to promote students' sense of urgency and thirst for knowledge. The learning mode in this study is characterized by "giving tasks." The students enhance their self-learning ability through completing tasks. We transform the learning process from the traditional teaching by teachers and students' passive reception to students' active thinking and learning. By doing so, the students with high learning initiative can learn and explore from the heart and gain better results. For example, the experimental group who watched videos for a longer time has completed the assigned tasks better than the control group.

\section{Conclusion}

In this study, we proposed an autonomous learning mode in accordance with a four-element teaching design for visual communication course, investigated the elements of the four-element teaching design, and integrated the four-element teaching design in visual communication. The proposed mode could promote students' autonomous learning and contribute to the communication between students and teachers. This teaching mode could emphasize students' autonomous learning and further enlighten and guide students' autonomous learning ability. We also propose a new Kmeans algorithm and analyzed students' autonomous learning behaviors. Finally, we compared the learning situations of the experimental and the control groups through course practice. We found that the experimental group who watched videos for a longer time showed a higher proportion of task completion than the control group. This result verified that the new learning mode could contribute to the improvement of students' autonomous learning ability. In the future study, we hope to improve the statistics of learning effect in the new mode and the overall understanding of its advantages and defects for further improvement. 


\section{Acknowledgement}

A Project Supported by key projects of the Ministry of Education of The National Education Science Plan (DIA190416).

\section{$7 \quad$ References}

[1] Zuiker, S. Visual Communication in Transition: Designing for New Media Literacies and Visual Culture Art Education across Activities and Settings. E-Learning and Digital Media, 2015, vol. 11(6), pp. 592-597. https://doi.org/10.2304/elea.2014.11.6.654

[2] Bowman, S. Visual Communication and Organizational Change: Interdisciplinary Approaches Linking Arts, Communication and Management. Journal of Thermal Analysis \& Calorimetry, 2015, vol. 78(2), pp. 415-426.

[3] Guo, L.X. Developing an Art Design Courseware Based on Visual Communication Technology and Computer Aided Instruction Technology. International Journal of Emerging Technologies in Learning, 2015, vol. 10(3), pp. 46-51. https://doi.org/10.3991/ijet.v10i3.45 $\underline{81}$

[4] Sunaga,Shoji. Education of Color Universal Design in Dept. Visual Communication Design, School of Design, Kyushu University (The Symposium on Action of the Color Universal Design Education,the 45th Annual Meeting). Journal of the Color Science Association of Japan, 2014, vol. 38(3), pp. 106-107.

[5] Rourke, A.J., Snepvangers K. Ecologies of practice in tertiary art and design: a review of two cases. Higher Education Skills \& Work Based Learning, 2016, vol. 6(1), pp. 69-85. https://doi.org/10.1108/heswbl-04-2015-0014

[6] Rintoul, J., James, D. 'That Tricky Subject': The Integration of Contextual Studies in preDegree Art and Design Education. International Journal of Art \& Design Education, 2017, vol. 36(2), pp. 215-225. https://doi.org/10.1111/jade.12077

[7] Kim, M.J., Ju, S.R., Lee, L. A Cross-Cultural and Interdisciplinary Collaboration in a Joint Design Studio. International Journal of Art \& Design Education, 2015, vol. 34(1), pp. 102120. https://doi.org/10.1111/jade.12019

[8] Ren, Y.J., \& Jiang, X. A mind map teaching mode for sports anatomy based on 3dbody. International Journal of Emerging Technologies in Learning, 2019, vol. 14(10), pp. 4-17. https://doi.org/10.3991/ijet.v14i10.10776

[9] Du, X.Y. Application of experiential teaching method in visual communication teaching. Science \& Technology Information, 2019, vol. 17(32), pp. 153-154.

[10] Li, M. Application and practice of modern apprenticeship in visual communication teaching in Higher Vocational Colleges. Jiangsu Salt Science \& Technology, 2019, vol. 46(3), pp. 130-131.

[11] Qiu, J., Hu, Y.X., Hu, H. Application of "task, problem, project" three driving method in Visual Communication Design Teaching. Learning week, 2018, vol. 384(36), pp. 7-8.

[12] Zhang, F. Application and thinking of five-star teaching mode in Visual Communication Design Teaching. China Rural education, 2019, vol. 31(23), pp. 119-120. 
Paper-Autonomous Learning Mode based on a Four-Element Teaching Design for Visual...

\section{Authors}

Yan Zhao is an associate professor in the University of Science and Technology Liaoning, Liaoning, China (plapla1001@ sina.com).

Yuemeng Luo is a Postgraduates in the University of Science and Technology Liaoning, Liaoning, China (plapla1001@ sina.com).

Article submitted 2020-06-27. Resubmitted 2020-08-28. Final acceptance 2020-08-30. Final version published as submitted by the authors. 